\title{
WHISKER-LIKE FORMATIONS IN Sn-3.0Ag-Pb ALLOYS
}

\begin{abstract}
In this study, different types of whisker-like formations of $\mathrm{Sn}-3.0 \mathrm{Ag}$ based alloy were presented. In the experimental process the amount of $\mathrm{Pb}$ element was changed between 1000 and $2000 \mathrm{ppm}$, and the furnace atmosphere and cooling rate were also modified. The novelty of this work was that whisker-like formations in macro scale size were experienced after an exothermic reaction. The whiskers of larger sizes than general provided opportunities to investigate the microstructure and the concentration nearby the whiskers. In addition, the whisker-like formations from $\mathrm{Sn}-\mathrm{Ag}$ based bulk material did not only consist of pure tin but tin and silver phases. The whisker-like growth appeared in several forms including hillock, spire and nodule shaped formations in accordance with parameters. It was observed that the compound phases were clustered in many cases mainly at hillocks.
\end{abstract}

Keywords: Sn-Ag alloy, soldering, whisker formation, microstructure analysis

\section{Introduction}

The phenomenon of whisker formation has a significant volume in the literature, several researchers have been studying it. The driving force to research primarily comes from the electronics industry [1-3], in which short circuits are caused by the whisker growth. As a result of research, the risk of the occurrence of whiskers has been significantly reduced. The pure tin surface is one of the most favorable ones for whiskers $[4,5]$, but they can also grow on tin-based alloys in various conditions $[5,6]$; however, this phenomenon has been observed on gold, silver and aluminum surfaces too [7]. For example, whisker growth can be caused by pressure [8-10]. The application of tin matte coating (by large grains with $\mathrm{C}$ content below $0.05 \%$ ) helps to reduce the risk of the formation of whiskers, also avoiding pure Sn coating, the use of porosity-free coating of $\mathrm{Ni}$, or a heat treatment of the surface $[3,5]$. Some of the typical formations of whiskers are shown in Fig. 1, such as hillock, nodule, spire or needles.

Initially, researchers thought that whisker formation was caused by different mechanisms of dislocations [3], and the crystals grow at the end, not at the root $[2,3]$. There is no need of electric field or specific atmosphere (whiskers grow even in vacuum) for whisker growth because the main conditions of the growing process are the compressive stress, oxide layer and the deformation of the microstructure $[2,5,6]$. Therefore, the phenomenon is often associated with the grain structure. It has also been proved that the presence of lead (from $1 \mathrm{wt} \%$ ) provides uniform grain structure which blocks the whisker formation
[4]. It is experienced that on Sn-Ag coatings there is no risk of whisker growth [6], but thermal shock cycles resulted in whisker formations on the surface of $\mathrm{Sn}-3.0 \mathrm{Ag}-0.5 \mathrm{Cu}$ solder alloy [5].

In this work, the based material ( $\mathrm{Sn}-3.0 \mathrm{Ag}$ alloy) is primarily not used as a soldering alloy in the industry, but for filling the solder bath of $\mathrm{Sn}-3.0 \mathrm{Ag}-0.5 \mathrm{Cu}$ alloy to reduce the increased copper content which is caused by the dissolution of $\mathrm{Cu}$ element from the components [7,11].

\section{Experimental}

Commercially available Sn-3.0Ag ('SAC300') solder was used for the experiments. The $\mathrm{Pb}$ content was changed between $0.1 \mathrm{wt} \%$ and $0.2 \mathrm{wt} \%$. The $\mathrm{Pb}$ element (which had $99,99 \mathrm{wt} \%$ purity) was proportioned by using an analytical scale, and each sample was $100 \mathrm{~g}$. The exact composition of the samples were determined by ICP method with triplicate measurement. The $\mathrm{Pb}$ concentrations of the melted samples are shown in Table 1 (in $95 \%$ confidence level).

TABLE 1

$\mathrm{Pb}$ content of the alloys produced by melting

\begin{tabular}{|c|c|c|c|c|c|c|c|c|c|c|}
\hline \hline ICP-OES & \multicolumn{10}{|c|}{ Samples } \\
\hline Results & $\# 1$ & $\# 2$ & $\# 3$ & $\# 4$ & $\# 5$ & $\# 6$ & $\# 7$ & $\# 8$ & $\# 9$ & $\# 10$ \\
\hline $\begin{array}{c}\text { Pb content, } \\
\text { wt } \%\end{array}$ & 0.097 & 0.101 & 0.095 & 0.119 & 0.123 & 0.117 & 0.147 & 0.144 & 0.037 & 0.040 \\
\hline $\begin{array}{c}\text { Uncertainty } \\
(95 \%)\end{array}$ & 0.004 & 0.005 & 0.002 & 0.002 & 0.007 & 0.004 & 0.006 & 0.005 & 0.004 & 0.003 \\
\hline
\end{tabular}

\footnotetext{
INSTITUTE OF PHYSICAL METALLURGY, METAL FORMING AND NANOTECHNOLOGY, UNIVERSITY OF MISKOLC, H-3515 MISKOLC-EGYETEMVÁROS, HUNGARY

\# Corresponding author: femkhd@uni-miskolc.hu
} 

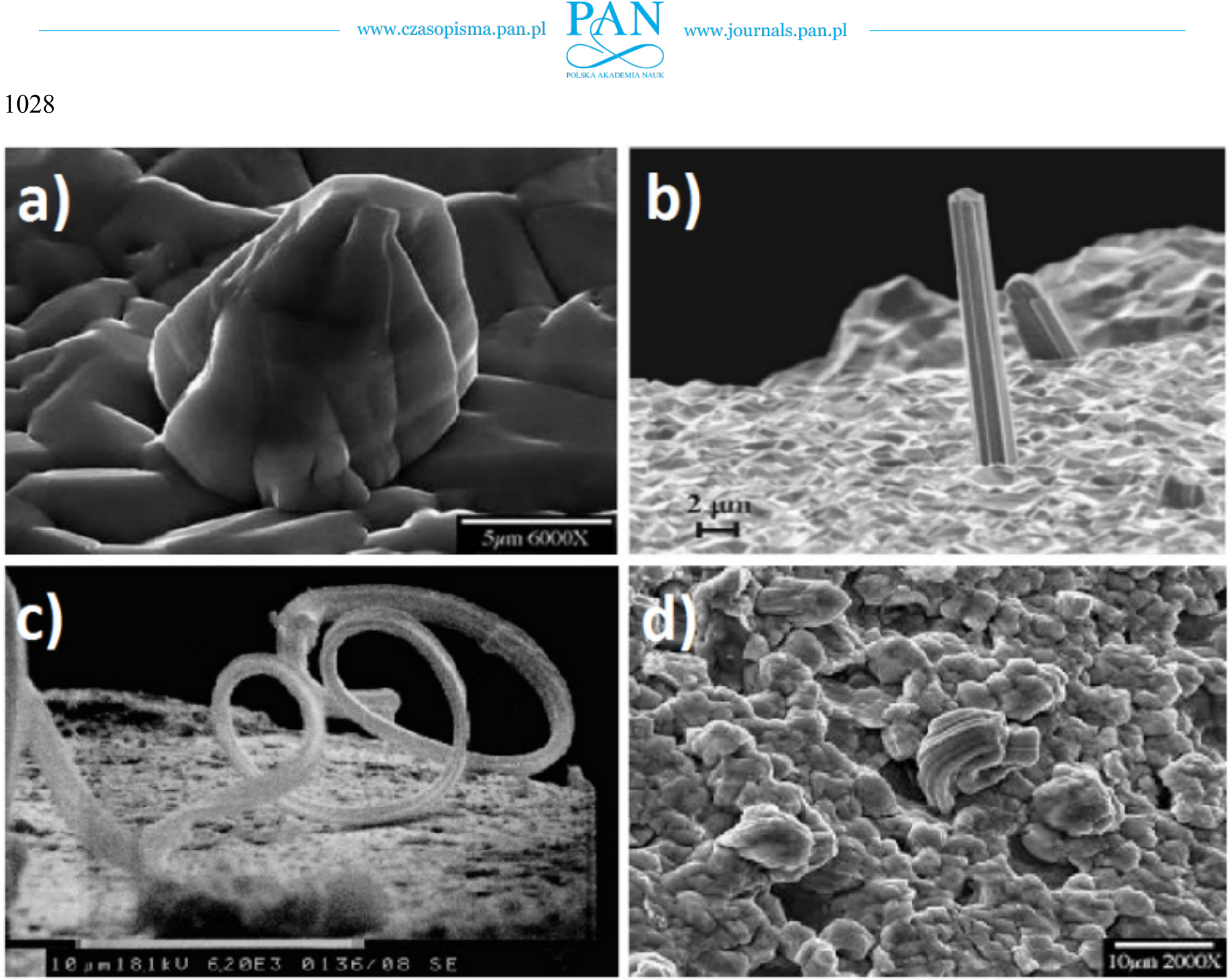

Fig. 1. Main types of whiskers [4-7] - a) Hillock, b) Needle, c) Spire, d) Nodule

TABLE 2

Experimental plan to study the whisker growth

\begin{tabular}{|c|c|c|c|c|c|c|}
\hline \hline & \multicolumn{2}{|c|}{$\begin{array}{c}\text { Atmosphere in } \\
\text { furnace }\end{array}$} & \multicolumn{2}{c|}{ Cooling process } & Results \\
\hline Sample & $\mathrm{Pb}, \mathrm{wt} \%$ & Normal & Vacuum & $\begin{array}{c}\text { in } \\
\text { Furnace }\end{array}$ & in Air & $\begin{array}{c}\text { Whisker } \\
\text { type }\end{array}$ \\
\hline$\# 1$ & 0,10 & + & & + & & spire \\
\hline$\# 2$ & 0,10 & + & & & + & hillock \\
\hline$\# 3$ & 0,10 & & + & + & & - \\
\hline$\# 4$ & 0,12 & + & & + & & nodule \\
\hline$\# 5$ & 0,12 & + & & & + & hillock \\
\hline$\# 6$ & 0,12 & & + & + & & - \\
\hline$\# 7$ & 0,15 & + & & + & & nodule \\
\hline$\# 8$ & 0,15 & & + & + & & - \\
\hline$\# 9$ & 0,04 & + & & & + & - \\
\hline$\# 10$ & 0,20 & + & & + & & - \\
\hline
\end{tabular}

The melting (alloying) process was carried out at $700^{\circ} \mathrm{C}$ with 2 hours holding at this temperature. The parameters of the alloying were changed, so 10 different samples were made. The atmosphere of the furnace was normal (without inert gas) or vacuum, while the cooling process was planned into the furnace or open air. The cooling rate in the range of $150-300^{\circ} \mathrm{C}$ was $\sim 5 \times 10^{-2} \mathrm{~K} / \mathrm{s}$ in the first case and $\sim 5 \times 10^{1} \mathrm{~K} / \mathrm{s}$ in the second case. The data of the samples are shown in Table 2.
The examinations were performed using light microscope (LM) with bright filed and differential interference contrast (DIC) technique. Micro-probe analysis (EDS) was also applied to measure the concentration of Ag element in Sn-matrix. The observed microstructures were characterized by publications taken into account [13-16].

\section{Results and discussion}

Based on the experimental plan it can be stated that the atmosphere had the main effect on the formation of whiskers. The way of cooling process determined the type of whiskers (such as spire, hillock or nodule). The concentration range of $\mathrm{Pb}$ element was between 0.1 and $0.15 \mathrm{wt} \%$ where whiskers was observed.

It can be stated that the base of whisker-like formations was the relatively thick oxide layer on the surface of solder material. It was achieved at normal atmosphere on the surface. The well-known whisker growing mechanism from the literature was justified by our results that the oxide layer pressures the bulk material (it is a compressive stress), and supports a recrystallization process (an exothermic reaction) which resulted in the formation of whiskers. In this paper the novelty is the investigation of macro-size whiskers. Fig. 2 shows one of the experimental results. The whisker-like formation (Sample 4) is compared with 

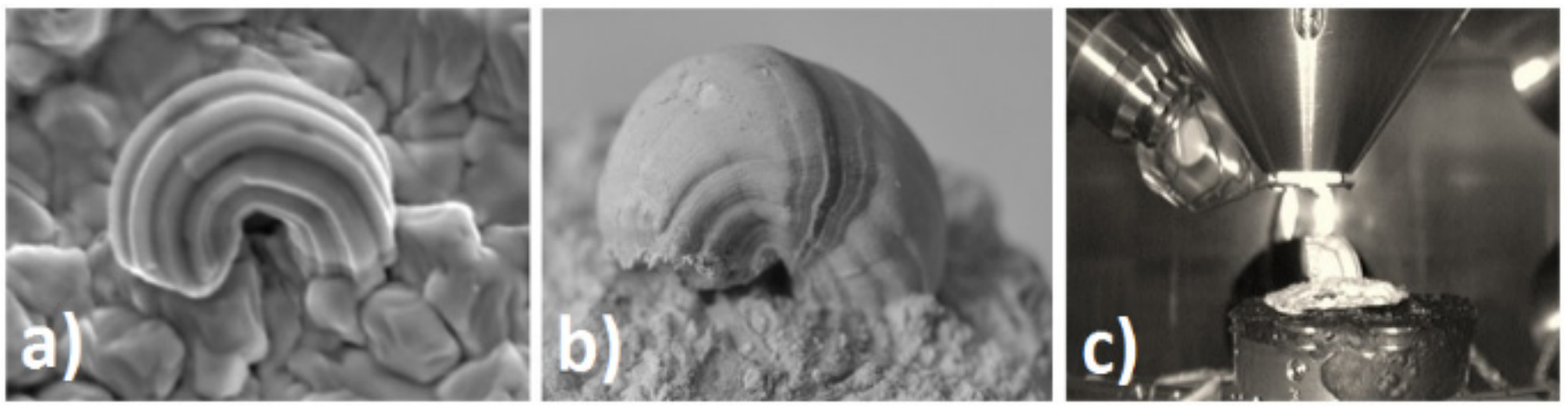

Fig. 2. 'Nodule' type whisker after the melting process $-\mathrm{a}) \sim 17 \mu \mathrm{m}$ long tin whisker from literature [12] b) $\sim 2 \mathrm{~cm}$ long tin-silver whisker (Sample \# 4), c) Examination of a whisker in SEM

an image from the literature [12]. The shape of both formation is nodule, which type appears when the oxide layer is relatively thick (because of slow cooling rate in normal atmosphere).

Table 2 shows that whisker-like formation was experienced in 5 out of 10 experimental samples at $1000 \mathrm{ppm}, 1200 \mathrm{ppm}$ and $1500 \mathrm{ppm} \mathrm{Pb}$ content. Based on the table it can be stated that whisker was not formed at vacuum atmosphere (because of the lack of thick oxide layer), whereas 'nodule' and 'spire' were formed at slow cooling rate (in furnace), while 'hillock' was formed at rapid cooling (in open air). Large 'nodule' was formed only at $1200 \mathrm{ppm} \mathrm{Pb}$ content. After the cooling process (e.g. Fig. 2b, Fig. 3) the microstructures were studied in more detail.

The composition of the whiskers and bulk materials were examined by micro probe analysis. Ag content was typically smaller at the root of the whiskers than at the end of the whiskers (confirming Linborg and Peach's theory [2]), but along the whiskers the average $\mathrm{Ag}$ content was less than $3 \mathrm{wt} \%$, the difference was about $0.5 \mathrm{wt} \%$. Based on the microscopic images (Fig. 4), it was observed that the increased $\mathrm{Pb}$ content resulted in more bushy $\mathrm{Ag}_{3} \mathrm{Sn}$ phases, while the slower cooling rate resulted in larger compounds (Fig. 5). The results of the measurement of the length of $\mathrm{Ag}_{3} \mathrm{Sn}$ phases showed that the amount of $\mathrm{Pb}$ had an effect on the length of tin-silver phases. Increased $\mathrm{Pb}$ content resulted in longer $\mathrm{Ag}_{3} \mathrm{Sn}$ phases.

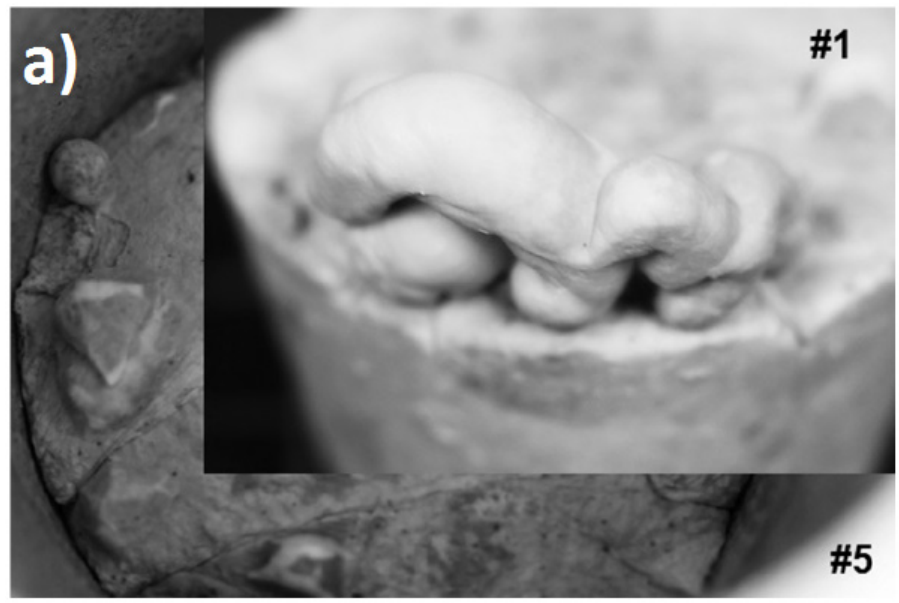

For the three different types of whiskers the microstructures were compared to each other (Fig. 6). It could be seen that in the case of 'nodule' type formation the $\mathrm{Ag}_{3} \mathrm{Sn}$ phases were randomly situated and independent, while in the case of 'spire' the phases were already clustered. Bushy phases could be observed at the 'hillock' type formations. It was obvious that the faster cooling process provided finer microstructure.

In electronic assemblies, where short cyclic thermal shocks affect the tin coat, the appearances of 'hillock' type whisker formation is supposedly increases based on our research.

\section{Conclusions}

In this presented work the goal was to show a reproducible investigation of macro scale size whisker-like formation which proves the possibility of large scale study of whisker formation. It can be stated that the phenomenon appeared especially at slow cooling $\left(10^{-2} \mathrm{~K} / \mathrm{s}\right.$ ), at normal furnace atmosphere (without inert gas), and the $\mathrm{Pb}$ content was between $1000 \mathrm{ppm}$ and $1500 \mathrm{ppm}$. The presented whisker-like formation is novelty because the Sn-3.0Ag alloy is exempt from whisker formation (as referred to previous works) and lead blocks the process of whisker formation (by uniform grain structure). Despite of these statements some set of the experimental parameters were found where whisker-

Fig. 3. Macro and LM images of samples - a) 'Spire' and 'hillocks' on the samples (\#1 and \#5) b) Cross-sectional LM mosaic from Sample \#4 

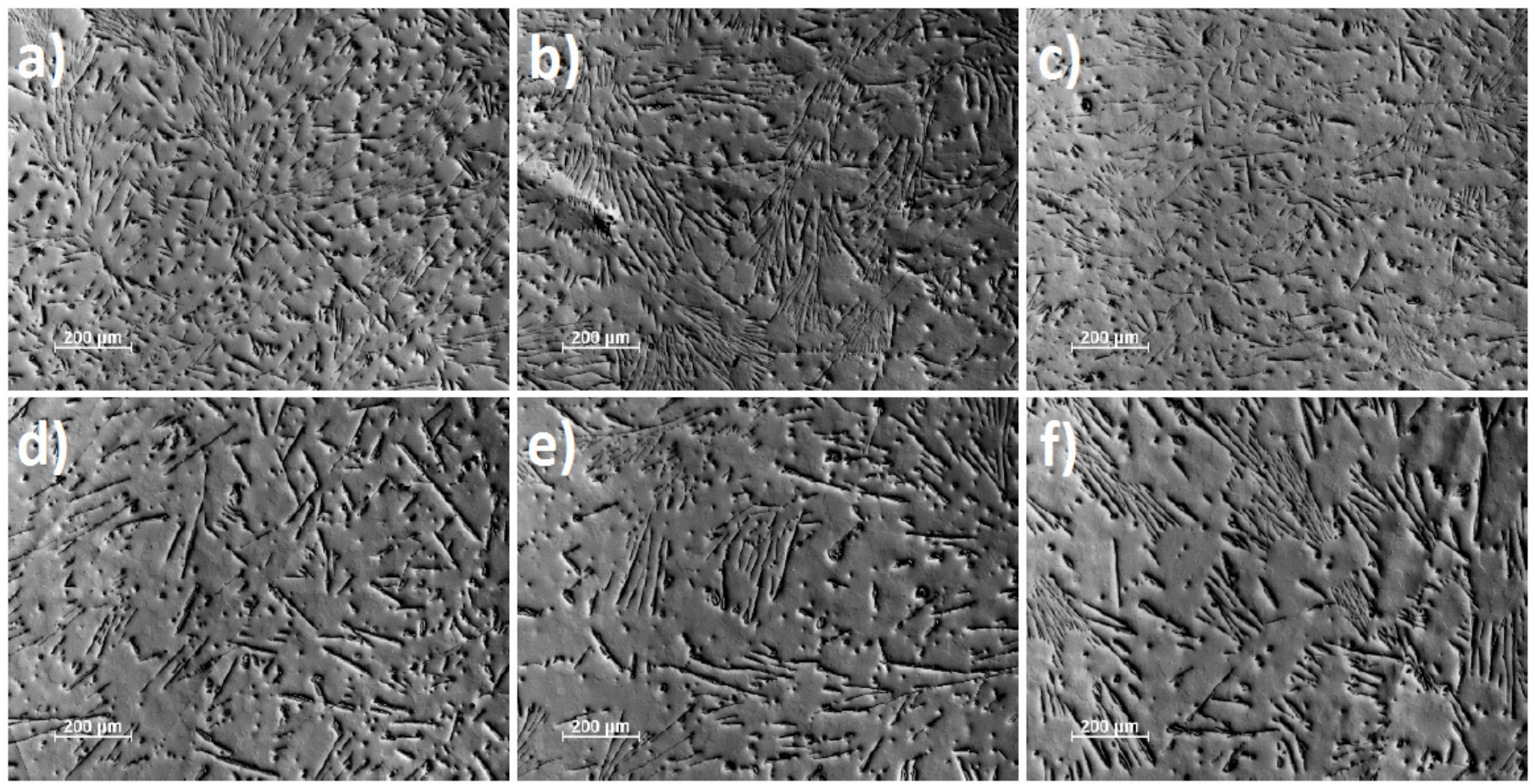

Fig. 4. A comparison of the matrix of the 5 (with whisker formation) samples and the base material (\#9) - with DIC contrast - a) Sample \#9 (Air, $0.04 \mathrm{wt} \% \mathrm{~Pb}$ ) b) Sample \#2 (Air, 0.1wt\%Pb) c) Sample \#5 (Air, 0.12wt\%Pb) d) Sample \#1 (Furnace, 0.1wt $\% \mathrm{~Pb}$ ) e) Sample \#4 (Furnace, $0.12 \mathrm{wt} \% \mathrm{~Pb}$ ) f) Sample \#7 (Furnace, $0.15 \mathrm{wt} \% \mathrm{~Pb}$ )
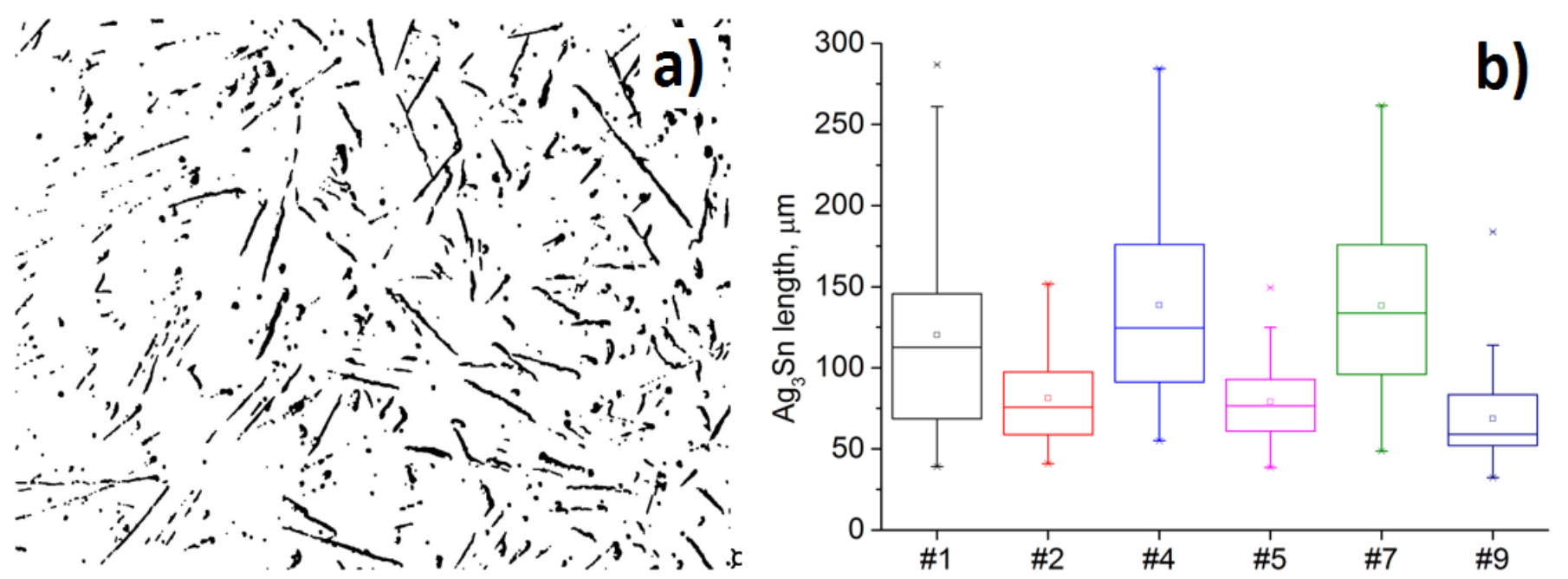

Fig. 5. Investigation of the sizes of $\mathrm{Ag}_{3} \mathrm{Sn}$ phases - a) Detected $\mathrm{Ag}_{3} \mathrm{Sn}$ phases in Sample \#1 b) $\mathrm{Ag}_{3} \mathrm{Sn}$ length of analyzed samples
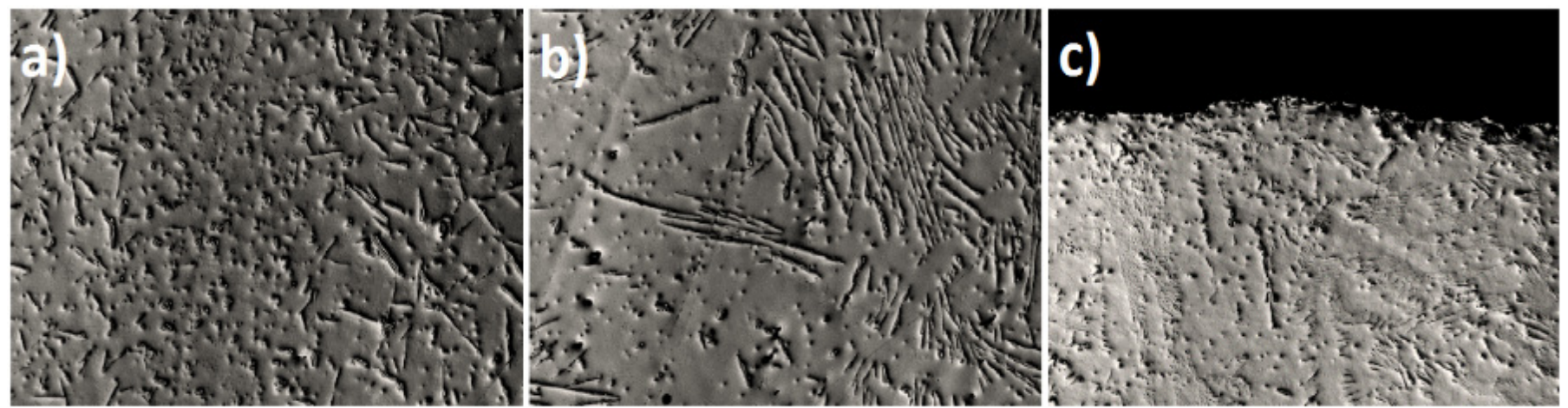

Fig. 6. LM photos of the microstructure of the different types of whiskers - with DIC contrast - a) nodule (\#1) b) spire (\#4) c) hillock (\#7) 
like formations appeared. It is found that the faster cooling rate resulted in 'hillock' type formation, and the slower rate favors the 'spire' and 'nodule' formations. The characterization of the $\mathrm{Ag}_{3} \mathrm{Sn}$ phases showed that in the case of 'nodule' the phases were random and independent, while in the case of 'hillock' the phases were clustered (and bushy). At the case of 'spire' type formation a little clustering was observed.

\section{Acknowledgments}

These work has been carried out as part of the TÁMOP-4.2.2.B-15/1/ KONV-2015-0003 project in the framework of the New Széchenyi Plan. The realization of this project is supported by the European Union, and cofinanced by the European Social Fund. The authors would like to express their gratitude to Tibor Szabó for the experimental support. The authors would also like to show their gratitude to the TERPLÁN Zénó Program supported by University of Miskolc.

\section{REFERENCES}

[1] K. Zeng, K.N. Tu, Mater. Sci. and Eng. R38, 55-105 (2002).

[2] J. Smetana, Electr. Pack. Manuf. 30/1, 11-22 (2007).

[3] D. Shangguan, Lead-Free Solder Interconnect Reliability, ASM International 2005.
[4] T. Kakeshita, K. Shimizu, R. Kawanaka, T. Hasegawa, J. Mater. Sci. 17/9, 2560-2566 (1982).

[5] A. Skwarek, K. Witek, J. Ratajczak, Microel. Reliab. 49/6, 569572 (2009).

[6] A. Baated, K. Hamasaki, S.S. Kim, K-S. Kim, K. Suganuma, J. Electr. Mater. 40/11, 2278-2289 (2009).

[7] K.J. Puttlitz, K.A. Stalter, Handbook of Lead-Free Solder Technology for Microelectronic Assemblies, New York 2004.

[8] A. Sycheva, A.L. Radanyi, Z. Gácsi, Mater. Sci. Forum, 790-791, 271-276 (2014).

[9] T. Shibutani, Q. Yu, M. Shiratori, M.G. Pecht, Microel. Reliab. 48, 1033-1039 (2008).

[10] A.L. Radanyi, A. Sycheva, Z. Gácsi, Arch. of Met. and Mater. 60/2, 1341-134 (2015).

[11] M. Judd, K. Brindley, Soldering in Electronic Assembly, Oxford 1999.

[12] Y. Nakadaira, S. Jeong, J. Shim, J. Seo, S. Min, T. Cho, S. Kang, S. Oh, Microel. Reliab. 47, 1928-1949 (2007).

[13] K.S. Kim, S.H. Huh, K. Suganuma, Mater. Sci. and Eng. A333, 106-114 (2002).

[14] J. Gong, C. Liu, P.P. Conway, V.V. Silberscmidt, Scrip. Mater. 61, 682-685 (2009)

[15] H-T. Lee, Y-F. Chen, J. Alloys and Comp. 509, 2510-2517 (2011).

[16] Q. Zhu, M. Sheng, L. Luo, Sold. and Surf. M. Tech. 12/2, 19-23 (2000). 